\title{
Variations in Plasma Electrolytes and Thirst Perception During the Menstrual Cycle
}

\author{
Janet Ogochukwu Nzoputam ${ }^{1}$, Ezeuchu Favour Udochukwu ${ }^{1}$, Emmanuel Amabebe ${ }^{2, *}$ \\ ${ }^{1}$ Department of Physiology, University of Benin, Benin City, Nigeria \\ ${ }^{2}$ Academic Unit of Reproductive and Developmental Medicine, University of Sheffield, Sheffield, UK
}

Email address:

emmanuelamabebe@yahoo.com (E. Amabebe)

${ }^{*}$ Corresponding author

\section{To cite this article:}

Janet Ogochukwu Nzoputam, Ezeuchu Favour Udochukwu, Emmanuel Amabebe. Variations in Plasma Electrolytes and Thirst Perception During the Menstrual Cycle. American Journal of Biomedical and Life Sciences. Vol. 7, No. 1, 2019, pp. 6-9.

doi: 10.11648/j.ajbls.20190701.12

Received: December 28, 2018; Accepted: January 23, 2019; Published: February 15, 2019

\begin{abstract}
Introduction: Electrolyte-dependent water retention associated with hormonal changes during the menstrual cycle may alter the normal reference intervals of plasma electrolytes with important effects on central nervous system, cardiovascular and renal functions. Hence, we sought to determine and compare plasma electrolytes (sodium, potassium, bicarbonate, chloride and urea) concentrations and thirst perception during different phases of the menstrual cycle. Methods: Blood samples obtained from the anti-cubital veins of 40 healthy females (18 - 25 years, 27 - 33 days menstrual cycle) on the 2nd (early follicular/menstrual, $\mathrm{n}=10$ ), 8th (late follicular, $\mathrm{n}=10$ ), 14th (ovulatory, $\mathrm{n}=10$ ) and 22nd (luteal, $\mathrm{n}=10$ ) day of the menstrual cycle were analysed for plasma electrolytes concentrations by photoelectric flame photometry. Thirst perception (TP) ratings were also obtained at the time of sample collection using the Visual Analogue Scale. Results: $\mathrm{Plasma}\left[\mathrm{Na}^{+}\right](P=$ $0.003)$ and $\left[\mathrm{Cl}^{-}\right](P=0.02)$ were highest during ovulation while the late follicular and luteal phases had the least $\left[\mathrm{Na}^{+}\right]$and $\left[\mathrm{Cl}^{-}\right]$ respectively. Plasma $\left[\mathrm{K}^{+}\right],\left[\mathrm{HCO}_{3}^{-}\right]$, and [urea] did not differ significantly in relation to the phase of menstrual cycle. In addition, TP increased in a phase-dependent non-significant manner until after ovulation. Conclusion: Plasma concentrations of sodium and chloride are increased during ovulation. This may be attributed to oestrogen-related salt retention, whereas the lower sodium and chloride concentrations observed in the luteal phase (compared to ovulation especially) could be due to the natriuretic action of progesterone.
\end{abstract}

Keywords: Menstrual Cycle, Plasma Electrolytes, Sodium, Chloride, Thirst

\section{Introduction}

Electrolyte-dependent water retention associated with hormonal changes during the menstrual cycle may alter the normal reference intervals of plasma electrolytes [1], with important effects on central nervous system, cardiovascular and renal functions [2-4]. Apart from their reproductive roles, oestrogen and progesterone also influence fluid regulation in young women [3].

Oestrogen induces increase in blood volume by lowering the operating point for arginine vasopressin (AVP) release and thirst. It also activates the renin-angiotensin-aldosterone system (RAAS) and consequently $\mathrm{Na}^{+}$and water reabsorption by stimulating the synthesis of angiotensinogen in the liver $[2,4-5]$. These effects are particularly obvious in high oestrogen states such as the late follicular and ovulatory phases of the menstrual cycle [4-5] and pregnancy [6-7]; and could be important for lactation subsequently [8].

On the other hand, progesterone can reduce the oestrogenrelated water and sodium retention by competing with aldosterone for the mineralocorticoid (type 1) receptors. It inhibits the aldosterone-dependent $\mathrm{Na}^{+}$reabsorption at the distal tubules of the nephron and cause a transient natriuresis [2-4]. As a result of this anti-mineralocorticoid and natriuretic action [5, 9-11], there is a compensatory increase in plasma renin concentration and activity, angiotensin II [5] and aldosterone concentration during the luteal phase of the menstrual cycle when progesterone levels are highest $[5,12]$. A similar progesterone-dependent increase in these RAAS components is observed during pregnancy but unlike the 
luteal phase of the menstrual cycle, angiotensinogen is also increased due to high placental oestrogen production [5].

The fluctuations and osmoregulatory activities of the female hormones during the menstrual cycle may resonate with variations in concentrations of plasma electrolytes and fluid balance with possible lifestyle adjustments especially during such periods. Hence, in this study, we sought to determine and compare concentrations of plasma electrolytes (sodium, potassium, bicarbonate, chloride and urea) and thirst perception during different phases of the menstrual cycle in young females.

\section{Methods}

\subsection{Study Participants}

This was a cross-sectional study involving forty healthy undergraduate female students (18 - 25 years) of the University of Benin, Nigeria with normal menstrual cycle length (27 - 33 days). Volunteers with irregular or abnormal menstrual cycle length (oligomenorrhea or polymenorrhea), dehydration, polydipsia, polyuria, diabetes, cardiovascular and kidney disease were excluded from the study. Also, lactating mothers, trained athletes and those on any form of hormonal contraceptive medications or dietary supplements such as vitamins were not included in the study. Eligible participants were recruited into the study after an informed consent was obtained. The University of Benin Research Ethics committee approved these studies.

\subsection{Sample Collection and Analyses}

Blood samples $(5 \mathrm{ml})$ were obtained from the anti-cubital veins of the study participants on the 2nd (early follicular/menstrual, $\mathrm{n}=10$ ), 8th (late follicular, $\mathrm{n}=10$ ), 14th (ovulatory, $\mathrm{n}=10$ ) and 22nd (luteal, $\mathrm{n}=10$ ) day of the menstrual cycle. The samples collected in to lithium heparin specimen bottles were analysed for sodium $\left(\mathrm{Na}^{+}\right)$, potassium $\left(\mathrm{K}^{+}\right)$, bicarbonate $\left(\mathrm{HCO}_{3}^{-}\right)$and urea $\left(\mathrm{CH}_{4} \mathrm{~N}_{2} \mathrm{O}^{-}\right)$ concentrations by photoelectric flame photometry using the improved FP-640 (Ningbo Hinotek Technology Co., Ltd, $\mathrm{CN})$.

Thirst perception (TP) ratings were also obtained at the time of sample collection using the Visual Analogue Scale (VAS). This involved asking the individual to indicate how thirsty she was by drawing a horizontal line on the VAS, which is an uncalibrated $10 \mathrm{~cm}$ vertical line with top marked "very thirsty" and the bottom "not thirsty".

\subsection{Statistical Analysis}

Differences in plasma electrolyte concentrations and TP ratings between the groups were determined by student's ttest and one-way analysis of variance (ANOVA) using GraphPad Prism 7.03 (GraphPad Software, Inc. CA, USA) statistical software package.

\section{Results}

As represented in table 1 and Figure 1, plasma $\left[\mathrm{Na}^{+}\right]$was highest in participants in the ovulatory phase compared to those in the other phases of the menstrual cycle $(P=0.003)$. There was a significant decrease in $\left[\mathrm{Na}^{+}\right]$from the early follicular to the late follicular phase $(P=0.045)$, which also had the lowest $\left[\mathrm{Na}^{+}\right]$.

Similarly, plasma $\left[\mathrm{Cl}^{-}\right]$was highest in participants in the ovulatory phase compared to those in other phases of the menstrual cycle $(P=0.02)$, particularly the luteal phase $(P=$ 0.02 ) that also had the least $\left[\mathrm{Cl}^{-}\right]$(Table 1 and Figure 2).

Plasma $\left[\mathrm{K}^{+}\right],\left[\mathrm{HCO}_{3}^{-}\right]$, and $\left[\mathrm{CH}_{4} \mathrm{~N}_{2} \mathrm{O}^{-}\right]$did not differ significantly in relation to the phase of menstrual cycle (Table 1).

In addition, TP increased in a phase-dependent nonsignificant manner until after the ovulatory phase and decreased in the luteal phase (Table 1 and Figure 3). There were similar TP ratings in participants in the early follicular and luteal phases.

Compared to those in the ovulatory phase, participants in the luteal phase had lower plasma $\left[\mathrm{Na}^{+}\right],\left[\mathrm{Cl}^{-}\right]$and $\mathrm{TP}$, though the difference in TP did not attain statistical significance.

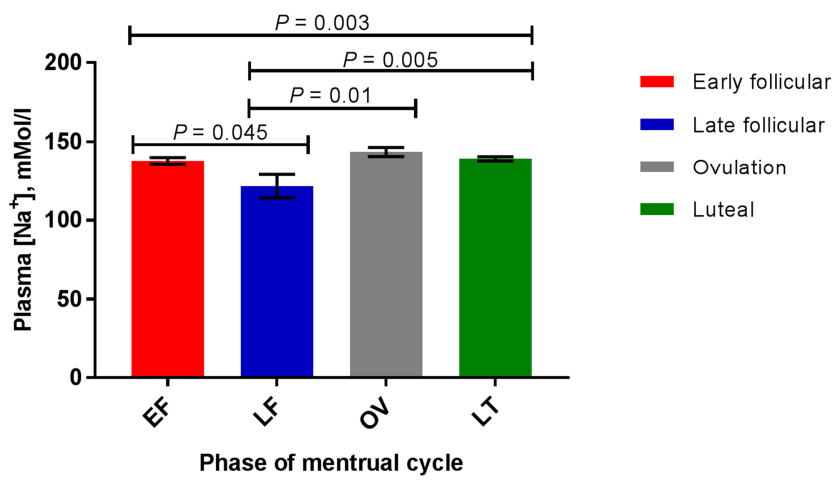

Figure 1. Plasma sodium concentration in different phases of the menstrual cycle. Plasma $\left[\mathrm{Na}^{+}\right]$was highest in participants in the ovulatory phase and lowest in the late follicular phase of the menstrual cycle.

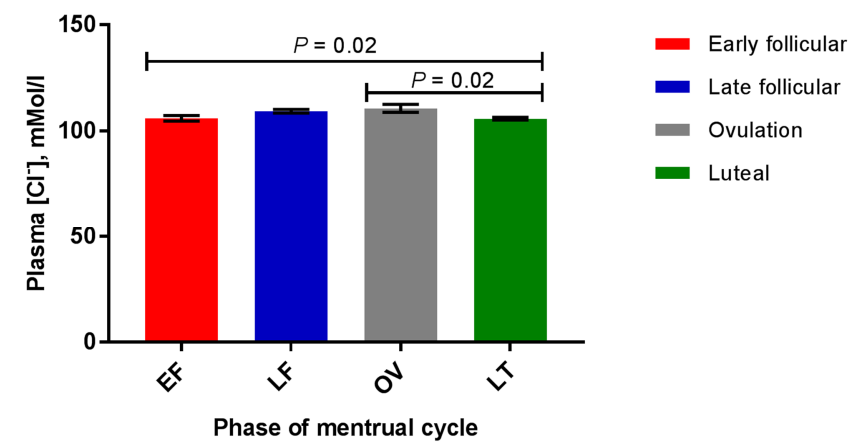

Figure 2. Plasma chloride concentration in different phases of the menstrual cycle. Plasma [Cl] was highest in participants in the ovulatory phase of the menstrual cycle compared to those in the luteal phase especially. 
Table 1. Plasma electrolyte concentration and thirst perception in different phases of menstrual cycle.

\begin{tabular}{|c|c|c|c|c|}
\hline & Early follicular & Late Follicular & Ovulation & Luteal \\
\hline \multicolumn{5}{|c|}{ Plasma electrolyte concentration } \\
\hline Sodium, mmol/1 & $138.2 \pm 2.13$ & $121.6 \pm 7.42$ & $143.8 \pm 2.81 * *$ & $139.4 \pm 1.30$ \\
\hline Chloride, $\mathrm{mmol} / 1$ & $106.0 \pm 1.35$ & $109.3 \pm 0.85$ & $110.7 \pm 1.85^{*}$ & $105.8 \pm 0.63$ \\
\hline Potassium, mmol/1 & $4.0 \pm 0.12$ & $4.0 \pm 0.07$ & $4.12 \pm 0.19$ & $4.1 \pm 0.07$ \\
\hline Bicarbonate, mmol/1 & $20.8 \pm 0.51$ & $19.7 \pm 0.45$ & $20.5 \pm 0.40$ & $20.4 \pm 0.22$ \\
\hline \multirow{2}{*}{$\begin{array}{l}\text { Urea, mg/dl } \\
\text { Thirst Perception, cm }\end{array}$} & $17.3 \pm 0.97$ & $19.0 \pm 0.99$ & $26.00 \pm 4.26$ & $21.1 \pm 1.56$ \\
\hline & $3.5+0.58$ & $44+072$ & $51+122$ & $36+060$ \\
\hline
\end{tabular}

Data presented as mean \pm standard error, $\mathrm{n}=10$ in each group. ${ }^{* *} P<0.01,{ }^{*} P<0.05$ (One-way ANOVA).

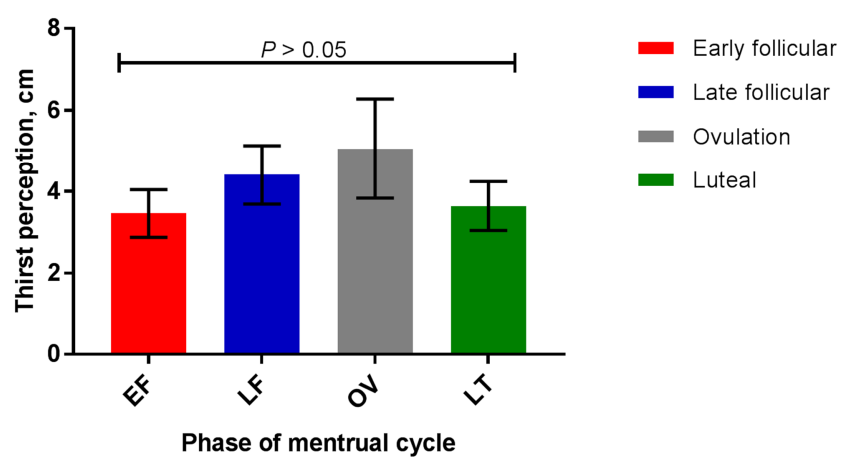

Figure 3. Thirst perception ratings in different phases of the menstrual cycle. TP increased in a phase-dependent non-significant manner until after ovulation and decreased in the luteal phase.

\section{Discussion}

This cross-sectional study determined and compared the concentrations of sodium, potassium, bicarbonate, chloride and urea in plasma of young non-pregnant females across different phases of the menstrual cycle. We also determined thirst sensation in relation to variations in electrolyte concentrations during the menstrual cycle. We observed that compared to the ovulatory phase, participants in the luteal phase had lower plasma $\left[\mathrm{Na}^{+}\right],\left[\mathrm{Cl}^{-}\right]$and $\mathrm{TP}$, though the decrease in TP was not statistically significant. There was also a decrease in $\left[\mathrm{Na}^{+}\right]$from the early to late follicular phase but TP increased in a non-significant manner up to the ovulatory phase before decreasing afterward.

The observed increase in plasma salt content and conscious desire to drink water (thirst) in the ovulatory phase where there is corresponding high oestrogen levels buttresses the osmoregulatory role of this hormone. The osmoregulatory action of oestrogen usually results in increased plasma volume and eventual reduction in plasma osmolality [4]. Our findings are supported by other reports of significantly lower serum sodium levels in the luteal phase compared to the ovulatory phase. Levels of $\mathrm{Na}^{+}, \mathrm{K}^{+}$and $\mathrm{Cl}^{-}$have been shown to increase significantly (up to peak levels) from follicular to ovulatory phase and fall thereafter in the luteal or premenstrual phase $[1,13-15]$. The increase in $\left[\mathrm{Na}^{+}\right]$and $\left[\mathrm{Cl}^{-}\right.$ ] in the ovulatory phase as oppose to the luteal phase is attributable to the established oestrogen-aldosteronedependent $\mathrm{Na}^{+}$retention and/or the absence or reduced antimineralocorticoid (natriuretic) activity of progesterone before ovulation [2-5, 9-11, 13]. Though Mira et al. [1] and Lanje et al. [16] had initially implicated the high amounts of AVP concentration observed during the luteal phase [17], AVP levels were measured on day 1 (early follicular) and days 1618 (luteal) only, omitting the ovulatory phase where oestrogen levels are usually at the peak. This may have masked the oestrogen-induced AVP release and the resultant osmoregulatory manifestations around the ovulatory phase.

A more recent study showed a downward trend in serum $\left[\mathrm{Na}^{+}\right]$from the menstrual to secretory phase of the menstrual cycle [18]. This trend corresponds with a decrease in plasma $\left[\mathrm{Na}^{+}\right]$from the early follicular (menstrual) to the late follicular (proliferative) phase as we have shown in our study. However, these authors did not report serum $\left[\mathrm{Na}^{+}\right]$ around ovulation and we observed a contrastingly higher plasma $\left[\mathrm{Na}^{+}\right]$in the luteal (secretory) phase compared to the late follicular phase.

In addition, we observed that the variations in $\mathrm{Na}^{+}$and $\mathrm{Cl}^{-}$ were not associated with variations in $\mathrm{K}^{+}, \mathrm{HCO}_{3}{ }^{-}$and urea. Like Lanje et al. [16], in our study, plasma $\left[\mathrm{K}^{+}\right]$was not significantly different among the groups though it decreased from the ovulatory to the luteal and then the follicular phase. However, a similar trend in decreasing $\left[\mathrm{K}^{+}\right]$was statistically significant in the studies conducted by Dadlani et al. [13]. Mishra and Kamal [18] also reported significantly higher serum $\left[\mathrm{K}^{+}\right]$in the secretory phase compared to the menstrual and proliferative phases.

Similar to Mira et al. [1], we did not observe a significant difference in urea concentration. However, in contrast to our observations and others [19-20], serum $\left[\mathrm{HCO}_{3}{ }^{-}\right]$has been shown to be higher in the late follicular and luteal phases and lower in the early follicular/menstrual and ovulatory phases [13]. Further studies are required to resolve these discrepancies in serum/plasma electrolyte concentrations in young females from different ethnic backgrounds and geographical locations.

Furthermore, though we observed a non-significant increasing trend in thirst perception from follicular to ovulatory phase and then a fall thereafter; the lower thirst perception in the postovulatory (luteal) phase may be described by the possible loss of $\mathrm{Na}^{+}$in excess of water [1], with a possible reduction in plasma osmolality. This could be through the antidiuretic action of the reported high AVP levels in the luteal phase of the menstrual cycle [17].

While our findings using this cross-sectional approach corroborate those of other studies and emphasises electrolyte and water balance especially during ovulation and 
postovulation, we realise that measurement of oestrogen, progesterone, AVP levels, aldosterone and plasma electrolytes simultaneously across the menstrual cycle in a larger cohort and in a longitudinal manner would provide a more comprehensive understanding of the osmoregulatory adaptations during this period. This can be compared with participants' body mass index, changes in blood pressure, as well as urine and sweat electrolyte excretion. Also, these adaptations may be significantly different in postmenopausal women, women with hormonal disturbances, trained athletes, women on hormonal contraceptives or certain vitamin supplements and therefore warrants further investigation.

\section{Conclusion}

The findings from this study suggest that plasma concentrations of sodium and chloride are increased during ovulation. This may be associated with increased thirst perception and attributed to oestrogen-related salt retention, whereas the lower sodium and chloride concentrations observed in the luteal phase (compared to ovulation especially) could be due to the natriuretic action of progesterone.

\section{Acknowledgements}

We are grateful to all the participants of this study, and acknowledge the support of staff of the Department of Chemical Pathology University of Benin Teaching hospital in conducting the electrolyte analyses. Parts of this work have been presented at Europhysiology (London, UK) (2018) Proc Physiol Soc 41, PCA224.

\section{References}

[1] M. Mira, P. M. Stewart, V. Gesbski, D. Llewellyn-Jones, S. F. Abraham. Changes in sodium and uric acid concentrations in plasma during the menstrual cycle. Clin Chem, 1984, 30 (3): 380-381.

[2] E. Boschitsch, S. Mayerhofer, D. Magometschnigg. Hypertension in women: the role of progesterone and aldosterone. Climacteric, 2010, 13 (4): 307-313.

[3] N. S. Stachenfeld. Sex hormone effects on body fluid regulation. Exerc Sport Sci Rev, 2008, 36 (3): 152-159.

[4] N. S. Stachenfeld. Hormonal changes during menopause and the impact on fluid regulation. Reprod Sci, 2014, 21 (5): 555561 .

[5] W. Oelkers. Effects of estrogens and progestogens on the renin-aldosterone system and blood pressure. Steroids, 1996, 61 (4): 166-171.
[6] F. H. Derkx, C. Steunkel, M. P. Schalekamp, W. Visser, I. H. Huisveld, M. A. Schalekamp. Immunoreactive renin, prorenin, and enzymatically active renin in plasma during pregnancy and in women taking oral contraceptives. J Clin Endocrinol Metab, 1986, 63: 1008-1015.

[7] M. D. Lindheimer, J. M. Davison. Osmoregulation, the secretion of arginine vasopressin and its metabolism during pregnancy. Eur J Endocrinol, 1995, 132 (2): 133-143.

[8] E. Amabebe, F. O. Robert, L. F. O. Obika. Osmoregulatory adaptations during lactation: Thirst, arginine vasopressin and plasma osmolality responses. Niger J Physiol Sci, 2017, 32 (2): 109-116.

[9] R. L. Landau and K. Lugibihl. Inhibition of the sodiumretaining influence of aldosterone by progesterone. J Clin Endocrinol Metab, 1958, 18: 1237-1245.

[10] W. Oelkers, M. Schöneshöfer, A. Blümel. Effects of progesterone and four synthetic progestagens on sodium balance and the renin-aldosterone system in man. J Clin Endocrinol Metab, 1974, 39: 882-889.

[11] G. Wambach and J. R. Higgins. Antimineralocorticoid action of progesterone in the rat: correlation of the effect on electrolyte excretion and interaction with renal mineralocorticoid receptors. Endocrinology, 1978, 102: 16861693.

[12] E. D. Szmuilowicz, G. K. Adler, J. S. Williams, D. E. Green, T. M. Yao, P. N. Hopkins, E. W. Seely. Relationship between Aldosterone and Progesterone in the Human Menstrual Cycle, J Clin Endocrinol Metab, 2006, 91 (10): 3981-3987.

[13] A. G. Dadlani, S. Chandwani, C. A. Desai, K. D. Pandya. Serum electrolytes during various phases of menstrual cycle. Indian J Physiol Pharmacol, 1982, 26 (4): 302-306.

[14] R. R. Overman, T. S. Hill, H. Jost. Ionic balance and correlated psycho-physiological measurements in premenstrual tensional states. Fed Proc, 1947, 6 (1 Pt 2): 174.

[15] R. S. Phillips, A. B. McCoord, W. T. Pommerenke. Serum Electrolytes in the Menstrual Cycle. Fert Steril, 1952, 3 (5): 402-418.

[16] M. A. Lanje, A. K. Bhutey, S. R. Kulkarni, U. P. Dhawle, A. S. Sande. Serum electrolytes during different phases of menstrual cycle. Int J Pharm Sci Res, 2010, 1 (10): 435-437.

[17] M. L. Forsling, M. Akerlund, P. Strömberg. Variations in plasma concentrations of vasopressin during the menstrual cycle. J Endocrinol, 1981, 89 (2): 263-266.

[18] A. Mishra and R. B. Kamal. Variations serum electrolyte level during different phases of menstrual cycle. Int J Biomed Res, 2015, 6 (07): 504-508.

[19] H. A. Frank and M. H. Carr. "Normal" serum electrolytes with a note on seasonal and menstrual variation. J Lab Clin Med, 1957, 49 (2): 246-252.

[20] R. L. Newman. Serum electrolytes in nonpregnant women. Obstet Gynecol, 1955, 6 (6): 615-618. 